\title{
Exposure to Volatile Organic Compounds and Use of Feminine Hygiene Products Among Reproductive-Aged Women in the United States
}

\author{
Ning Ding, $\mathrm{MPH},{ }^{1}$ Stuart Batterman, $\mathrm{PhD},{ }^{2,3}$ and Sung Kyun Park, $\mathrm{ScD}^{1,2}$
}

\begin{abstract}
Background: Feminine hygiene products (FHPs) are personal care products widely used by women. A few studies have detected some volatile organic compounds (VOCs) in FHPs, but no previous epidemiological studies have linked use of these products to human exposure to VOCs using biomarkers. Therefore, we evaluated whether the use of FHPs was associated with VOC exposures among reproductive-aged women in the United States.

Materials and Methods: Data on 2432 women aged 20-49 years from National Health and Nutrition Examination Survey 2001-2004 were utilized. Self-reported use of feminine products (tampons, sanitary napkins, vaginal douches, sprays, powders, wipes/towelettes, and other products) was obtained from questionnaires. Survey-weighted linear regression models were used to estimate percent changes in VOC whole blood concentrations and $95 \%$ confidence intervals (CIs).

Results: Black women had significantly more use of vaginal douching and significantly higher whole blood concentrations of 1,4-dichlorobenzene (DCB) $(p<0.0001)$. After adjusting for confounders, we observed a dose-response relationship between the frequency of vaginal douching in the past 6 months and 1,4-DCB concentrations. Compared with never users, women with occasional use ( $\leq 1 \mathrm{time/month})$ of vaginal douching had $18 \%$ (95\% CI: $-12 \%$ to $59 \%$ ) higher concentrations, and those with frequent use ( $\geq 2$ time/month) had $81 \%$ (95\% CI: $2 \%$ to $221 \%$ ) higher concentrations of 1,4-DCB ( $p$ for trend $=0.04$ ). Use of feminine powder in the past month was significantly associated with $36 \%$ (95\% CI: $0.4 \%$ to $83 \%$ ) higher concentrations of ethylbenzene.

Conclusions: Our findings suggest that differences in whole blood VOC concentrations might be explained by feminine hygiene practices. The presence of environmental chemicals in FHPs warrants further examination.
\end{abstract}

Keywords: feminine hygiene practices, volatile organic compounds, health disparities

\section{Introduction}

$\mathbf{I}_{\mathrm{p}}^{\mathrm{N}}$ N THE UNITED StATES, exposure to volatile organic compounds (VOCs) occurs in both indoor and outdoor settings, although indoor levels are often higher, a result of the presence and use of many common products that contain VOCs. ${ }^{1}$ VOCs are ingredients in products such as fragrances, personal care products such as nail polish and deodorants, moth repellents, air fresheners, paints, caulks, fuels, and automotive products. ${ }^{2,3}$ VOCs may be absorbed through dermal contact, inhalation, or ingestion.

Certain VOCs have been associated with acute toxic effects, such as neurological disorders and respiratory symp- toms ${ }^{4}$; long-term exposure can also cause cancers and adverse effects on reproductive systems. ${ }^{5}$ For example, based on sufficient evidence of carcinogenicity from studies in experimental animals, 1,4-dichlorobenzene (DCB) and styrene are reasonably anticipated to be human carcinogens, ${ }^{6}$ and may induce menstrual disturbances, spontaneous abortions, and congenital malformations. ${ }^{7,8}$ The major sources of DCB in the United States are deodorants, mothballs, and the production of polyphenylene sulfide resins. ${ }^{9}$ DCB exists in the vapor phase with an atmospheric half-life of 1 month. In addition, chronic exposure to ethylbenzene, which is used primarily in the manufacturing procedure of styrene, can adversely affect the central nervous system. ${ }^{10}$

Departments of ${ }^{1}$ Epidemiology and ${ }^{2}$ Environmental Health Sciences, School of Public Health, University of Michigan, Ann Arbor, Michigan.

${ }^{3}$ Department of Water Resources and Environmental Engineering, College of Engineering, Michigan, Ann Arbor, Michigan. 
Given the concern over VOC toxicity, it is important to identify VOC sources that can be targeted for exposure reduction strategies. Fragranced consumer products are a known pathway of VOC exposure. Chemical exposure to VOCs occurring through the use of feminine hygiene products (FHPs) is a potential public health concern and modifiable source. Here, we define these products as personal care products used by women for menstruation, vaginal discharge, and other purposes related to the vulva and vagina, such as menstrual pads, tampons, wipes, sprays, and douches.

In August 2014, the consumer group Women's Voices for Earth (WVE) found menstrual pads emitted styrene, chloromethane, and chloroform. ${ }^{11}$ FHPs that are used vaginally, such as douches, tampons, and menstrual pads, may be an unrecognized exposure of VOCs, especially for reproductive-aged women who use multiple products daily. Feminine hygiene practices may influence chemical exposure disparities since black women reported vaginal douching, which is intravaginal cleansing with a liquid solution, more frequently than white women and other racial/ethnic groups. ${ }^{12,13}$

No previous study has examined associations between the use of FHPs and population exposure to VOCs. With greater awareness of these chemicals in consumer products, ${ }^{14}$ the unique characteristic of the vaginal region that can result in very high rates of chemical uptake, ${ }^{15,16}$ and the potential for health disparities among various groups of women through the culturally influenced use of these products, it is important to investigate the chemical exposure from these commonly used products, especially among reproductiveaged women.

This study uses self-reported questionnaire data along with whole blood concentrations of VOC measured in reproductiveaged women (20-49 years) in the National Health and Nutrition Examination Survey (NHANES) during the period of 2001-2004. Study objectives include the following: exploring sociodemographic and racial/ethnic disparities in whole blood concentrations of VOCs; examining sociodemographic differences in use of FHPs in the past month, including tampons, menstrual pads, vaginal douches, feminine sprays, powders, wipes/towelettes, and other products, as well as douching frequency over the past 6 months; evaluating and comparing whole blood concentrations of VOCs among women with or without use of these products in the past month; and assessing the possibility of a dose-exposure relationship between the frequency of vaginal douche use in the past 6 months and whole blood VOC concentrations. We hypothesized that use of FHPs and frequent douching might contribute to increased exposure to VOCs.

\section{Materials and Methods}

\section{Data source and sample}

We pooled data from NHANES, which is a nationally representative sample of the civilian, noninstitutionalized U.S. population conducted by the U.S. Centers for Disease Control and Prevention (CDC). The 2001-2002 and 20032004 cycles were included because they were the only ones in which data were collected on use of FHPs. The study participants were restricted to women aged 20-49 years with self-reported data on FHP use $(n=2432)$.

\section{Whole blood VOC measurements}

Blood samples were collected from a subsample of participants (approximately one-third of the population) at the mobile examination center (MEC). Whole blood concentrations of VOCs were measured by headspace solid-phase microextraction/gas chromatography/isotope dilution mass spectrometry following published methods. ${ }^{17-19}$ Limits of detection (LODs) range from 19 to $92 \mathrm{pg} / \mathrm{mL}$. VOCs with detection frequencies $<50 \%$ were excluded from the final analyses. The final analysis included eight VOCs, namely bromoform, bromodichloromethane, benzene, chloroform, dibromochloromethane, 1,4-DCB, and ethylbenzene. Values below the LOD were replaced with $\mathrm{LOD} / \sqrt{2} .^{20}$ The chemical groups and their descriptive statistics are listed in Supplementary Table S1.

\section{Reproductive health questionnaire}

Reproductive health survey data were collected at the MEC interview room administered by interviewers on the day of the health examination. The questionnaire contains questions for women on reproductive health, including menstrual history, current pregnancy, and pregnancy history, as well as feminine hygiene practices. Women were asked, "During the past month, have you used any of the following products for feminine hygiene?' If the participants responded positively, then they were asked, "Which of these products did you use?" with options including tampons, sanitary napkins, vaginal douches, feminine sprays, feminine powders, feminine cleansing wipes/towelettes, and/or other special cleansing products. For each type of FHP, a binary variable was created to indicate use in the past month.

Data on frequency of FHP use were available only for vaginal douche. Douching was evaluated by asking, "During the past 6 months, did you douche? By douching, we mean putting a substance into your vagina either for routine cleansing or for vaginal irritation or signs of infection?" Given a positive response, the woman was then asked, "During the past 6 months, how often did you douche?" with options of $\geq 5$ times/month, 2-4 times/month, 1 time per month, or $\leq 1$ time/month. We classified participants into three frequency groups; that is, nonusers, occasional users ( $\leq 1$ time/month), and frequent users ( $\geq 2$ times/month).

\section{Covariates}

The potential covariates included in the statistical analyses were determined a priori based on a literature review. We used a Directed Acyclic Graph (www.dagitty.net/dags.html) to show the hypothesized relations between use of FHPs, confounders, and chemical concentration outcomes (Supplementary Figure S1). Possible confounders taken into account include age at interview, race/ethnicity, body mass index (BMI), smoking, educational attainment, poverty-income ratio, physical activity, hormone use, pregnancy, menopause, and the use of other personal care products, for example, cosmetics.

The minimal and sufficient adjustment set identified in our final analyses were age at interview, race/ethnicity, BMI, a ratio of family income to poverty, pregnancy status, and menopausal status, to minimize the possibility of overadjustment and maximize sampling size and power. Race/ethnicity 
was classified into white, black, Mexican American, other Hispanic, and other racial/ethnic group. Educational attainment was identified as less than high school, high school graduate, or higher levels. The ratio of family income to poverty $<1.0$ indicates that income for the respective household is below the official definition of poverty, while a ratio of $\geq 1.00$ indicates income above the poverty level. Pregnancy status at examination was categorized into positive laboratory pregnancy test, self-reported pregnant, or self-reported not pregnant. Menopausal status was categorized into premenopause, natural menopause, and surgical menopause due to hysterectomy and/or oophorectomy.

\section{Statistical analyses}

We performed natural log-transformation on chemical concentrations to help ensure normality of outcomes. Surveyweighted linear regression models were used to examine the association between VOC concentrations and use of FHPs. Effect estimate was interpreted as a percent change in chemical concentrations by feminine product use as a $\left(\mathrm{e}^{\beta}-1\right) \times 100$ with $95 \%$ confidence intervals (CIs) estimated as $\left(\mathrm{e}^{\beta \pm 1.96 \times S E}-1\right) \times 100$, where $\beta$ and $\mathrm{SE}$ are the estimated regression coefficient and standard error (SE), respectively. The 4-year sample weights were calculated as one half of the NHANES laboratory weights, taking into account the complex survey designs and nonresponse of eligible participants. The significance tests were two sided, with a type I error rate of 0.05 .

Substitutions for concentrations below the LOD results with a constant value could produce questionable descriptive statistics and bias effect estimates. Alternative approaches include extrapolation using Blom estimate, iterative maximum likelihood estimation, and the use of the reverse Kaplan-Meier estimator by treating unobserved data as left censored. $^{21-30}$ In a sensitivity analysis, reverse KaplanMeier estimates were used to address the issue of left censoring. In brief, the calculation uses a product of probabilities of being lower than a given value, conditional on being lower than a slightly higher value. Quantile estimates (25th, 50th, and 75 th percentiles) were computed and compared with values replaced with $\mathrm{LOD} / \sqrt{2}$. (See results in the Supplementary Table S2). All analyses were conducted using SAS version 9.4 (SAS Institute, Inc., Cary, NC).

\section{Results}

The mean age of the study population was $34.9(\mathrm{SE}=0.3)$ years, and Mexican Americans were significantly younger than other racial/ethnic groups (Table $1, p<0.0001$ ). NonHispanic black women had higher BMI with a mean of 31.2 $(\mathrm{SE}=0.4) \mathrm{kg} / \mathrm{m}^{2}$, and Mexican Americans had the lowest educational attainment. Compared with other racial/ethnic groups, non-Hispanic blacks and Mexican Americans were

Table 1. Survey-Weighted Demographic and Socioeconomic Characteristics and Use of Feminine Hygiene Products in the Past Month by Race/Ethnicity Among U.S. Reproductive-Aged Women of 20-49 Years, National Health and Nutrition Examination Survey 2001-2004 ( $N=2432)$

\begin{tabular}{|c|c|c|c|c|c|c|c|}
\hline & $\mathrm{n}$ & $\begin{array}{c}\text { White } \\
(\mathrm{n}=1166)\end{array}$ & $\begin{array}{c}\text { Black } \\
(\mathrm{n}=511)\end{array}$ & $\begin{array}{l}\text { Mexican } \\
\text { American } \\
(\mathrm{n}=547)\end{array}$ & $\begin{array}{c}\text { Other } \\
\text { Hispanic } \\
(\mathrm{n}=107)\end{array}$ & $\begin{array}{c}\text { Other } \\
\text { racelethnicity } \\
(\mathrm{n}=101)\end{array}$ & $\mathrm{p}-$ Value $^{\mathrm{a}}$ \\
\hline Age (years), mean (SE) & 2432 & $35.4(0.3)$ & $34.3(0.3)$ & $32.6(0.4)$ & $34.6(0.9)$ & $33.7(1.0)$ & $<0.0001$ \\
\hline BMI $\left(\mathrm{kg} / \mathrm{m}^{2}\right)$, mean $(\mathrm{SE})$ & 2393 & $27.3(0.3)$ & $31.2(0.4)$ & $29.2(0.4)$ & $29.1(0.5)$ & $25.8(0.5)$ & $<0.0001$ \\
\hline Educational attainment, $\%$ & 2431 & & & & & & $<0.0001$ \\
\hline$<$ HS graduate & 572 & 9 & 25 & 47 & 16 & 11 & \\
\hline HS graduate & 544 & 24 & 26 & 21 & 23 & 16 & \\
\hline$>$ HS graduate & 1315 & 67 & 49 & 32 & 61 & 73 & \\
\hline Income-to-poverty ratio, $\%$ & 2318 & & & & & & $<0.0001$ \\
\hline $\mathrm{Z}$ & 509 & 13 & 31 & 32 & 27 & 13 & \\
\hline$\geq 1.00$ & 1809 & 87 & 69 & 68 & 73 & 87 & \\
\hline Pregnancy status, $\%$ & 2379 & & & & & & $<0.0001$ \\
\hline Yes & 459 & 5 & 8 & 10 & 2 & 14 & \\
\hline No & 1920 & 95 & 92 & 90 & 98 & 86 & \\
\hline Menopausal status, \% & 2431 & & & & & & 0.09 \\
\hline Premenopause & 2198 & 88 & 87 & 94 & 88 & 89 & \\
\hline Natural menopause & 54 & 3 & 2 & 2 & 6 & 2 & \\
\hline Surgical menopause & 179 & 9 & 11 & 4 & 6 & 9 & \\
\hline \multicolumn{8}{|c|}{ Use of feminine hygiene products in the past month, \% } \\
\hline Tampon & 851 & 53 & 36 & 25 & 29 & 33 & $<0.0001$ \\
\hline Sanitary napkin & 1320 & 56 & 37 & 67 & 63 & 54 & 0.003 \\
\hline Vaginal douche & 408 & 13 & 39 & 13 & 14 & 9 & $<0.0001$ \\
\hline Feminine spray & 146 & 4 & 16 & 3 & 11 & 4 & $<0.0001$ \\
\hline Feminine powder & 93 & 2 & 11 & 1 & 4 & 3 & $<0.0001$ \\
\hline Wipes/towelettes & 251 & 8 & 18 & 11 & 16 & 6 & $<0.0001$ \\
\hline Other products & 101 & 0 & 0 & 0 & 0 & 100 & NA \\
\hline
\end{tabular}

${ }^{\mathrm{a}} p$-Values to examine differences by racial/ethnic groups for continuous variables: F-test; for categorical variables: Rao-Scott chi-square test.

BMI, body mass index; HS, high school; NA, not available; SE, standard error. 
more likely to have family income below the poverty threshold. Mexican American and other race/ethnicity identities tended to be premenopausal. Black women were more likely to receive hysterectomy and/or oophorectomy before their natural menopause. No significant difference was found in pregnancy status by race/ethnicity $(p=0.09)$.

Considering use of FHPs in the past month, non-Hispanic white women reported significantly higher use of tampons, whereas non-Hispanic black women had significantly higher use of vaginal douche, feminine spray, feminine powder, wipes/towelettes, and other products (Table 1). Similarly, non-Hispanic black women used vaginal douching more frequently than other racial/ethnic groups. Note that women could report use of several types of products simultaneously. For instance, among the 2432 women in the study, 755 (22\%) reported no use of either tampon or menstrual pad, $826(32 \%)$ used menstrual pads only, 357 (19\%) used tampons only, and $494(27 \%)$ reported use of both tampons and pads in the past month.

Table 2 shows frequency of vaginal douching during the previous 6 months in relation to demographic and socioeconomic characteristics. Women who reported more frequent douche tended to be older than never users $(p=0.03)$, and were more likely to have significantly higher BMI with a mean of $30.0(\mathrm{SE}=0.7) \mathrm{kg} / \mathrm{m}^{2}(p=0.0002)$. Compared with other racial/ethnic groups, non-Hispanic black women had higher frequency of vaginal douching. Frequent users had lower educational attainment and often had incomes below the poverty threshold. Women reported using douche as a type of vaginal cleansing during pregnancy, whereas pregnant women reported less frequent douching $(p=0.003)$.
Women who reached menopause due to hysterectomy and/or oophorectomy were more likely to use douche in the past 6 months after their surgery in comparison with premenopausal women and women who reached natural menopause $(p<0.0001)$

VOC concentrations by racial/ethnic groups are presented in Supplementary Table S3. Black and Mexican American women had significantly higher geometric mean concentrations of 1,4-DCB $(p<0.0001)$. Women with other race/ ethnicity identities had higher concentrations of bromodichloromethane $(p=0.004)$, chloroform $(p=0.02)$, dibromochloromethane $(p=0.003)$, toluene $(p<0.0001)$, and $\mathrm{m}-/$ p-xylene $(p<0.0001)$.

After adjusting for age at interview, race/ethnicity, educational attainment, income-to-poverty ratio, BMI, pregnancy status, and menopausal status, use of feminine powder in the past month was significantly associated with $35.6 \%$ (95\% CI: $0.4 \%$ to $83.2 \%$ ) higher whole blood concentrations of ethylbenzene (Table 3). Feminine powder use was also related to $107.9 \%$ (95\% CI: $-9.4 \%$ to $377.1 \%$ ) higher whole blood concentrations of 1,4-DCB; however, it did not reach statistical significance. We observed a significant and positive dose-exposure relationship between frequency of vaginal douching in the past 6 months and whole blood concentrations of $1,4-\mathrm{DCB}$ ( $p$-trend $=0.04$, Table 4 ). In adjusted models, women with occasional use $(\leq 1$ per month) of vaginal douching in the past 6 months had a $18 \%$ (95\% CI: $-12 \%$ to $59 \%$ ) increase, and frequent users ( $\geq 2$ per month) had a $81 \%$ (95\% CI: $2 \%$ to $221 \%$ ) increase in whole blood concentrations of 1,4-DCB, compared with never users.

Table 2. Survey-Weighted Demographic and Socioeconomic Characteristics and Frequency of Vaginal Douching in the Previous 6 Months by Race/Ethnicity Among U.S. Reproductive-Aged Women of 20-49 Years, National Health and Nutrition Examination Survey 2001-2004 (N=2430)

\begin{tabular}{|c|c|c|c|c|c|}
\hline & $\mathrm{N}$ & $\begin{array}{c}\text { Never } \\
(\mathrm{n}=1828)\end{array}$ & $\leq 1$ per month & $\begin{array}{l}\geq 2 \text { per month } \\
(\mathrm{n}=214)\end{array}$ & $\mathrm{p}-$ Value \\
\hline Age (years), mean (SE) & 2430 & $34.5(0.4)$ & $35.6(0.4)$ & $36.9(0.7)$ & 0.03 \\
\hline BMI $\left(\mathrm{kg} / \mathrm{m}^{2}\right)$, mean $(\mathrm{SE})$ & 2391 & $27.4(0.2)$ & $29.7(0.5)$ & $30.0(0.7)$ & 0.0002 \\
\hline Race/ethnicity, \% & 2430 & & & & $<0.0001$ \\
\hline White & 1165 & 80 & 14 & 6 & \\
\hline Black & 511 & 47 & 29 & 24 & \\
\hline Mexican American & 546 & 81 & 15 & 4 & \\
\hline Other Hispanic & 107 & 82 & 13 & 5 & \\
\hline Other racial groups & 101 & 82 & 10 & 8 & \\
\hline Educational attainment, \% & 2429 & & & & $<0.0001$ \\
\hline$<$ HS graduate & 572 & 65 & 18 & 17 & \\
\hline HS graduate & 543 & 68 & 22 & 10 & \\
\hline$>\mathrm{HS}$ graduate & 1314 & 82 & 13 & 5 & \\
\hline Income-to-poverty ratio, $\%$ & 2317 & & & & $<0.0001$ \\
\hline$<1.00$ & 508 & 78 & 15 & 7 & \\
\hline$\geq 1.00$ & 1809 & 66 & 19 & 15 & \\
\hline Pregnancy status, \% & 2377 & & & & 0.003 \\
\hline Pregnant & 457 & 88 & 8 & 4 & \\
\hline Nonpregnant & 1920 & 75 & 16 & 9 & \\
\hline Menopausal status, $\%$ & 2429 & & & & $<0.0001$ \\
\hline Premenopause & 2196 & 76 & 17 & 7 & \\
\hline Natural menopause & 54 & 78 & 15 & 7 & \\
\hline Surgical menopause & 179 & 60 & 22 & 18 & \\
\hline
\end{tabular}

${ }^{\text {a }} p$-Values to examine differences by racial/ethnic groups for continuous variables: F-test; for categorical variables: Rao-Scott chi-square test. 


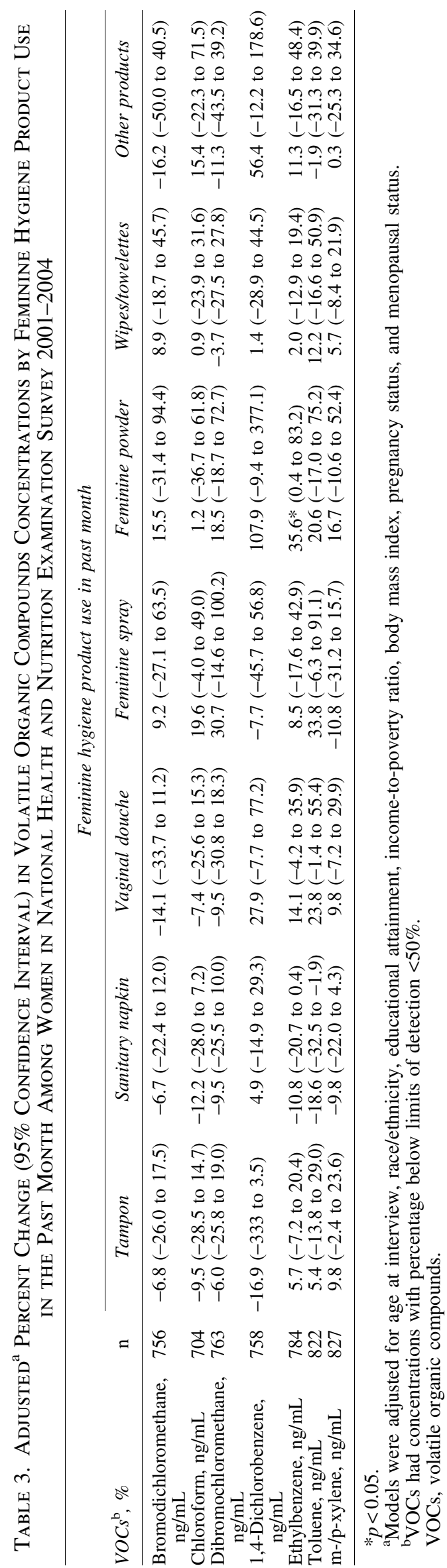

\section{Discussion}

In this representative sample of the U.S. reproductive-aged women, vaginal douching was associated with higher exposure of 1,4-DCB, suggesting that use of this product may be a potential source of $1,4-\mathrm{DCB}$ exposure or may be related to activities that increase 1,4-DCB exposure. Given the significant and monotonic relationship, women who reported an average frequency of douching two or more times per month had whole blood 1,4-DCB concentrations $81 \%$ higher than never users. Similarly, use of feminine powders might contribute to higher exposure to ethylbenzene. Our results indicate the need for additional research to evaluate these products as a potential and modifiable pathway of VOC exposure.

In our study sample, $4 \%$ of the U.S. pregnant women aged 20-49 years reported to perform vaginal douching two or more times per month in the past 6 months. Among frequent douche users, $59 \%$ were non-Hispanic black. VOC exposure has also been related to race/ethnicity; for example, non-Hispanic blacks and Mexican Americans had higher exposure to 1, 4-DCB than non-Hispanic white and other racial/ethnic groups. Factors associated with douching behavior in our study include older age, higher BMI, being non-Hispanic black, having less than high school education, living under the poverty threshold, and experiencing surgical menopause. These findings are consistent with previous studies on douching patterns examining socioeconomic and racial/ethnic characteristics. ${ }^{31}$

Previous animal studies have suggested reproductive and developmental effects of 1,4-DCB. A previous animal study evaluated DCB's endocrine-disrupting potential using a zebrafish vitellogenin assay with 1,4-DCB solvent added to the aquaria found to cause dose-dependent increases in $\beta$-galactosidase production, similar to a human estrogen hormone $17 \beta$-estradiol; and significantly reduced gonad weight relative to overall body weight. ${ }^{32}$ In female rats and their matured offspring, the ovary weights were detected to decrease $\sim 80 \%$ through coexposure to 1,4-DCB and 1,1-dichloro-2,2bis(p-chlorophenyl)-ehtylene (p,p'-DDE). ${ }^{8}$ Furthermore, rats and rabbits with the highest doses had delayed cervical ossification among their next generation. ${ }^{33,34} \mathrm{~A}$ two-generation rat model also suggested reduced birth weight and higher mortality rates among pups due to maternal 1,4-DCB exposure. ${ }^{35}$ Several case studies report in humans with accidental exposure to DCB through mothball ingestion ${ }^{36-39}$; however, no epidemiological study has been conducted to explore effects of DCB on reproductive health, including localized effects on the vaginal epithelium or microbiome. Thus, the public health implications of our findings may warrant further investigation.

In addition to douching behavior, use of feminine powder might contribute to higher whole blood concentrations of ethylbenzene. No previous studies have assessed VOC contents in feminine or baby powder. Talc is one of the major ingredients in feminine powder. Nerín et al. detected ethylbenzene released from microwave-safe plastic containers made of polypropylene $20 \%$ talcum powder. ${ }^{40}$ Ethylbenzene is commonly detected in gasoline, carpet glues, paints, and automobile products. It is possible that the observed association between ethylbenzene and use of feminine powder might be explained by use of these consumer products. However, it was not feasible to explore dose-response relationships because frequency of feminine powder use was not collected in NHANES. 
Table 4. Frequency of Vaginal Douching in the Past 6 Months and Adjusted Pa Percent Change (95\% Confidence Interval) in the Concentrations of Volatile Organic Compounds Among Women in National Health and Nutrition Examination Survey 2001-2004

\begin{tabular}{|c|c|c|c|c|c|}
\hline \multirow[b]{2}{*}{$V O C s^{\mathrm{b}}, \%$} & \multicolumn{4}{|c|}{ Average douching frequency in past 6 months } & \multirow[b]{2}{*}{$\mathrm{p}$-Value } \\
\hline & $\mathrm{n}$ & Never & $\leq 1$ per month & $\geq 2$ per month & \\
\hline Bromodichloromethane, $\mathrm{ng} / \mathrm{mL}$ & 756 & Reference & $-4.2(-29.3$ to 29.7$)$ & $-0.9(-29.7$ to 39.6$)$ & 0.84 \\
\hline Chloroform, $\mathrm{ng} / \mathrm{mL}$ & 704 & Reference & $-1.3(-18.3$ to 19.2$)$ & $16.2(-21.6$ to 72.1$)$ & 0.52 \\
\hline Dibromochloromethane, $\mathrm{ng} / \mathrm{mL}$ & 763 & Reference & $14.2(-17.6$ to 58.1$)$ & $-2.4(-35.1$ to 46.6$)$ & 0.71 \\
\hline 1,4-Dichlorobenzene, $\mathrm{ng} / \mathrm{mL}$ & 758 & Reference & $18.1(-12.0$ to 58.7$)$ & $81.0(2.2$ to 220.8$)$ & 0.04 \\
\hline Ethylbenzene, $\mathrm{ng} / \mathrm{mL}$ & 784 & Reference & $8.9(-6.5$ to 26.7$)$ & $5.5(-18.8$ to 37.1$)$ & 0.46 \\
\hline Toluene, $\mathrm{ng} / \mathrm{mL}$ & 822 & Reference & $27.0(-2.0$ to 64.6$)$ & $10.5(-22.6$ to 57.7$)$ & 0.19 \\
\hline $\mathrm{m}$-/p-xylene, ng/mL & 827 & Reference & $14.1(-5.4$ to 37.7$)$ & $-7.5(-25.8$ to 15.5$)$ & 0.78 \\
\hline
\end{tabular}

${ }^{a}$ Models were adjusted for age at interview, race/ethnicity, educational attainment, income-to-poverty ratio, body mass index, pregnancy status, and menopausal status.

${ }^{b}$ VOCs had concentrations with percentage below limits of detection $<50 \%$.

DCB and ethylbenzene are used in personal care products to retain fragrances. ${ }^{41,42}$ Since vaginal douches and powders often contain fragrances, these materials may be unrecognized sources of exposure to these VOCs. Very few of the fragrance ingredients have been disclosed to the consumers, or reviewed by the International Fragrance Association (IFRA) or its research arm, the Research Institute for Fragrance Materials. ${ }^{43}$ Even for chemicals included in the IFRA safety program, standards are also incomplete and inconsistently applied. Given the potential toxicity of these compounds, it is important for the manufacturers to disclose the identity of materials contained in their products, rather than general terms such as "cleaning agent" or "fragrance."

Vaginal and vulvar tissues are highly permeable to chemicals given the absence of a keratinized stratum corneum, loosely packed skin layers, ${ }^{44-46}$ and abundance of arteries, blood vessels, and lymphatic vessels in the walls of vagina. ${ }^{16}$ Vaginal and vulvar tissues are more permeable than exposed skin due to differences in tissue structure, occlusion, hydration, and susceptibility to friction. ${ }^{15,47}$ Meanwhile, VOCs entering vaginal tissues may undergo less metabolism than other tissues, including oral mucosa. ${ }^{48}$

However, FHPs intended for use on vaginal and vulvar tissues, which are highly permeable to VOCs and other chemicals, are marketed and sold with little or no information assuring the ingredients they contain are safe. Menstrual tampons and pads are identified as "Medical Devices" by the U.S. Food \& Drug Administration, ${ }^{49}$ although there are no government requirements to disclose all ingredients and manufacturing byproducts to consumers. ${ }^{50}$ The American College of Obstetricians and Gynecologists and the U.S. Department of Health and Human Services Office on Women's Health recommend refraining from douching and using other personal hygiene products to prevent getting a urinary tract infection. ${ }^{51}$ Nonetheless, these guidelines do not discuss potential chemical hazards and their potential impacts on reproductive health.

A previous research detected VOCs in menstrual pads, ${ }^{52}$ in contrast we did not observe associations between VOCs and the use of tampons and/or menstrual pads. Several factors might mask associations. The null association between tampon use and VOC exposure might be due to the reasons that FHPs are used episodically during menstrual cycle, and the lifetime of VOCs in blood is short, for example, DCB and ethylbenzene have a half-life of 1 month and 2 days, ${ }^{53,54}$ respectively. A binary indicator of FHP use in the past month may not adequately capture the time window of exposure. In addition, there are many sources of VOC exposure. Finally, VOC composition is likely to vary between products.

FHPs are unlikely to be major exposure sources of some VOCs. Bromodichloromethane, dibromochloromethane, and chloroform are disinfection byproducts formed when drinking water is disinfected using chlorine. Contact with chlorinated water through drinking, showering, bathing, swimming, dish and clothes washing has been shown to increase exposure to these trihalomethanes. ${ }^{55-58} \mathrm{We}$ also do not expect that FHPs are important source of benzene, toluene, ethylbenzene, xylene (BTEX), and styrene. These VOCs are components of tobacco smoke, gasoline, paints, solvents, and other common sources. 2,4-Dimethyl-furan and cotinine are smoking biomarkers. ${ }^{59}$ We found similar results with further control for smoking status (never, current, and former smokers) (data not shown).

While we observed a significant dose-response relationship between DCB concentrations and frequencies of vaginal douching in the past 6 months (Table 4), we failed to observe a significant association when asked about the use of vaginal douching in the past month as a binary response (Table 3). Exposure misclassification and loss in power may explain the discrepancies.

\section{Strengths and limitations}

Our study has several strengths. This is one of the first studies to explore FHPs as a potential exposure source of VOCs. We included a nationally representative population, and accounted for the complex survey designs in our analyses, including racial/ethnic, socioeconomic, and geographic diversity. Thus, we expect generalizability of study findings to U.S. reproductive-aged women. A DAG was constructed to account for potential confounding using a minimal and sufficient adjustment set, though we still cannot rule out the possibility of residual confounding. Data on frequency of douching provided the opportunity to examine the dose-exposure relationships and support a plausible association. 
Study limitations include the cross-sectional nature of NHANES data, which cannot rule out the possibility of reverse causality. Owing to data availability, other sources that might be responsible for VOC exposure could not be evaluated; for example, DCB exposure through the use of mothballs or toilet deodorants. Our models were adjusted for this by using the DAG to ascertain the minimal sufficient adjustment set $^{60}$ and account for use of personal care or household products. In addition, VOCs with detection rates $<50 \%$ were excluded in the analyses, which limits our ability to evaluate some relationships, for example, possibly including the relatively few women who use feminine sprays and wipes containing these VOCs, especially if there are few other exposure sources of these VOCs.

Moreover, FHP use data were collected in 2001-2004, which might not reflect current feminine hygiene practices, and it is possible that the industry has changed the manufacturing processes and formulations since then. Thus, more recent data on FHP use, composition, and biological monitoring are needed to confirm our findings. In addition, FHP use data were collected through questionnaires, which are subject to recall bias and misclassification. The timing of feminine hygiene practices can also be influenced by sexual activity, vaginal symptoms, and the menstrual cycle. Unfortunately, NHANES only measured frequency of douching rather than frequency of use of other feminine products. Future research is needed with a longitudinal setting and repeated data collection on chemical exposure and use of FHPs during a menstrual cycle. Finally, NHANES did not collect data on FHP use among Asian American or indigenous women. Further surveys should include the unstudied minority groups.

The vaginal exposure route might be significant for chemicals other than VOCs. Branch et al. observed 152\% higher urinary concentrations of monoethyl phthalates, used as fragrance chemicals, among frequent douche users than nonusers. ${ }^{12}$ FHPs are widely used and represent $\sim \$ 3$ billion per year market. ${ }^{61}$ Our results suggest the need for disclosure and/or testing of specific ingredients, comprehensive screening tests to characterize exposures, improved guidance regarding the douching and other practices, and dissemination of this information.

Clearly, the safest approach is to let vagina clean itself, which it does by secreting mucus, rather than using vaginal douching, wipes, or other products.

\section{Conclusions}

Non-Hispanic black women had higher whole blood concentrations of 1,4-DCB and more likely to report frequent douche use. We also found a positive and monotonic relationship between frequency of vaginal douching and 1,4DCB concentrations, indicating douche as a potential source of this VOC and might account for racial/ethnic differences among reproductive-aged women. Use of feminine powder might also lead to increased whole blood concentrations of ethylbenzene. Following the American College of Obstetricians and Gynecologists and the U.S. Department of Health and Human Services Office, ${ }^{51}$ we suggest that douching or use of feminine powder be discouraged, especially during pregnancy. Manufacturers should disclose all ingredients, and screening tests to evaluate chemicals in FHPs should be considered.

\section{Authors' Contributions}

All authors conceptualized and designed the study. N.D. and Dr. S.K.P. formulated the methods for statistical analyses. N.D. conducted the statistical analyses and drafted the initial article. All authors reviewed the article, had significant input into the editing and interpretation of data, and read and approved the final article.

\section{Author Disclosure Statement}

No author has a conflict of interest, and we certify that no party has a direct interest in the result of this research, or has conferred or will confer a benefit on us or any organization with which we are associated.

\section{Funding Information}

This work was supported by grants from the National Institute of Environmental Health Sciences P30-ES017885 and the Centers for Disease Control and Prevention/National Institute for Occupational Safety and Health Grant T42$\mathrm{OH} 008455$.

\section{Supplementary Material}

Supplementary Figure S1

Supplementary Table S1

Supplementary Table S2

Supplementary Table S3

\section{References}

1. Salthammer T, Zhang Y, Mo J, Koch HM, Weschler CJ. Assessing human exposure to organic pollutants in the indoor environment. Angew Chemie Int Ed 2018;57:1222812263.

2. Churchill JE, Ashley DL, Kaye WE. Recent chemical exposures and blood volatile organic compound levels in a large population-based sample. Arch Environ Health 2001; 56:157-166.

3. Division of Toxicology and Human Health Science. Agency for Toxic Substances and Disease Registry. Centers for Disease Control and Prevention. Public Health Statement for Toluene. 2015.

4. US EPA. Risk assessment and modeling-Air toxics risk assessment reference library. Available at: https://www .epa.gov/fera/risk-assessment-and-modeling-air-toxics-riskassessment- reference-library Accessed June 11, 2019.

5. Johnson BL. A review of the effects of hazardous waste on reproductive health. Am J Obstet Gynecol 1999;181:S12S16.

6. US Department of Health and Human Services. 14th report on carcinogens (RoC). 2016.

7. Lindbohm ML. Effects of styrene on the reproductive health of women: A review. IARC Sci Publ 1993:163-169.

8. Makita Y. Effects of perinatal, combined exposure to 1, 4-dichlorobenzene and 1,1- dichloro-2,2-bis(p-chlorophenyl) ethylene on rat female reproductive system. Basic Clin Pharmacol Toxicol 2008;102:360-364.

9. Division of Toxicology and Human Health Science. Agency for Toxic Substances and Disease Registry. Centers for Disease Control and Prevention. Public Health Statement for Dichlorobenzenes. 2006.

10. Division of Toxicology and Human Health Science. Agency for Toxic Substances and Disease Registry. 
Centers for Disease Control and Prevention. Public Health Statement for Ethylbenzene. 2010.

11. Testing reveals toxic chemicals in always pads. Available at: www.womensvoices.org/2014/10/13/testing-revealstoxic-chemicals-in-procter-gambles-always-pads/ Accessed February 21, 2018.

12. Branch F, Woodruff TJ, Mitro SD, Zota AR. Vaginal douching and racial/ethnic disparities in phthalates exposures among reproductive-aged women: National Health and Nutrition Examination Survey 2001-2004. Environ Health 2015;14:57.

13. Duty SM, Ackerman RM, Calafat AM, Hauser R. Personal care product use predicts urinary concentrations of some phthalate monoesters. Environ Health Perspect 2005;113: 1530-1535.

14. Park CJ, Barakat R, Ulanov A, et al. Sanitary pads and diapers contain higher phthalate contents than those in common commercial plastic products. Reprod Toxicol 2019;84:114-121.

15. Hussain A, Ahsan F. The vagina as a route for systemic drug delivery. J Control Release 2005;103:301-313.

16. Richardson JL, Illum L. (D) Routes of delivery: Case studies. (8) The vaginal route of peptide and protein drug delivery. Adv Drug Deliv Rev 1992;8:341-366.

17. Chambers DM, McElprang DO, Waterhouse MG, Blount BC. An improved approach for accurate quantitation of benzene, toluene, ethylbenzene, xylene, and styrene in blood. Anal Chem 2006;78:5375-5383.

18. Blount BC, Kobelski RJ, McElprang DO, et al. Quantification of 31 volatile organic compounds in whole blood using solid-phase microextraction and gas chromatographymass spectrometry. J Chromatogr B Anal Technol Biomed Life Sci 2006;832:292-301.

19. Blount B, Sampson EJ. Laboratory procedure manual volatile organic compounds (VOCs) whole blood solid phase microextraction GCMS public release data set information. 2003. Available at: https://wwwn.cdc.gov/nchs/data/nhanes/ 2003-2004/labmethods/104voc_c_met_blood.pdf Accessed June 15, 2018.

20. NHANES Environmental Chemical Data TutorialImportant Analytic Considerations and Limitations. Available at: https://www.cdc.gov/nchs/tutorials/environmental/critical_ issues/limitations/Task2.htm Accessed March 3, 2019.

21. Newman MC, Dixon PM, Looney BB, Pinder JE. Estimating mean and variance for environmental samples with below detection limit observations. J Am Water Resour Assoc 1989;25:905-916.

22. Cohen AC. Simplified estimators for the normal distribution when samples are singly censored or truncated. Technometrics 1959;1:217-237.

23. Finkelstein MM, Verma DK. Exposure estimation in the presence of nondetectable values: Another look. Am Ind Hyg Assoc J 2001;62:195-198.

24. Gilliom RJ, Helsel DR. Estimation of distributional parameters for censored trace level water quality data: 1. Estimation techniques. Water Resour Res 1986;22:135-146.

25. Helsel DR. Less than obvious: Statistical treatment of data below the detection limit. Environ Sci Technol 1990;24: 1766-1774.

26. Hornung RW, Reed LD. Estimation of average concentration in the presence of nondetectable values. Appl Occup Environ Hyg 1990;5:46-51.

27. Lambert D, Peterson B, Terpenning I. Nondetects, detection limits, and the probability of detection. J Am Stat Assoc 1991;86:266-277.
28. Lyles RH, Fan D, Chuachoowong R. Correlation coefficient estimation involving a left censored laboratory assay variable. Stat Med 2001;20:2921-2933.

29. Gillespie BW, Chen Q, Reichert H, et al. Estimating population distributions when some data are below a limit of detection by using a reverse kaplan-meier estimator. Epidemiology 2010;21(SUPPL. 4):S64-S70.

30. Turnbull BW. The empirical distribution function with arbitrarily grouped, censored and truncated data. J R Stat Soc Ser B 1976;38:290-295.

31. Arbour M, Corwin EJ, Salsberry P. Douching patterns in women related to socioeconomic and racial/ethnic characteristics. J Obstet Gynecol Neonatal Nurs 2009;38:577-585.

32. Versonnen BJ, Arijs K, Verslycke T, Lema W, Janssen $\mathrm{CR}$. In vitro and in vivo estrogenicity and toxicity of o-, m-, and p-dichlorobenzene. Environ Toxicol Chem 2003; 22:329-335.

33. Hayes W, Gushow T, John J. Para-dichlorobenzeneInhalation teratology study in rabbits: File No. K-1323(12). Un-Published study Prepared by Dow Chemical USA. 1982:350.

34. Neeper-Bradley T, Kubena F. Developmental toxicity study of maternally inhaled paradichlorobenzene vapor in $\mathrm{CD}$ rats: Lab Project Number: 91N0110. Unpublished study Prepared by Union Carbide Chemicals and Plastics Co., Inc. 1992:381.

35. Tyl R, Neeper-Bradley T. Paradichlorobenzene-Two generation reproduction study of inhaled paradichlorobenzene in sprague-dawley (CD) rats 86-81-90605. Unpublished study prepared by Union Carbide Bushy Run Res Center. 1989:757.

36. Dubey D, Sharma VD, Pass SE, Sawhney A, Stüve O. Paradichlorobenzene toxicity-A review of potential neurotoxic manifestations. Ther Adv Neurol Disord 2014;7: 177-187.

37. Kumar N, Dale LC, Wijdicks EFM. Mothball mayhem: Relapsing toxic leukoencephalopathy due to p-dichlorobenzene neurotoxicity. Ann Intern Med 2009;150:362-363.

38. Feuillet L, Mallet S, Spadari M. Twin girls with neurocutaneous symptoms caused by mothball intoxication. N Engl J Med 2006;355:423-424.

39. Campbell DM, Davidson RJ. Toxic haemolytic anaemia in pregnancy due to a pica for paradichlorobenzene. J Obstet Gynaecol Br Commonw 1970;77:657-659.

40. Nerín C, Acosta D, Rubio C. Potential migration release of volatile compounds from plastic containers destined for food use in microwave ovens. Food Addit Contam 2002;19: 594-601.

41. Ethylbenzene. TGSC information system. Available at: www.thegoodscentscompany.com/data/rw1022281.html\# tosafiu Accessed June 10, 2019.

42. Women's Voice for the Earth. Secret Scents. 2013.

43. Women's Voice for the Earth. Unpacking the Fragrance Industry: Policy Failures, the Trade Secret Myth and Public Health. 2015.

44. Lesch CA, Squier CA, Cruchley A, Williams DM, Speight P. The permeability of human oral mucosa and skin to water. J Dent Res 1989;68:1345-1349.

45. Squier CA. Penetration of nicotine and nitrosonornicotine across porcine oral mucosa. J Appl Toxicol 1986;6:123-128.

46. Squier CA, Hall BK. The permeability of skin and oral mucosa to water and horseradish peroxidase as related to the thickness of the permeability barrier. J Invest Dermatol 1985;84:176-179. 
47. Farage M, Maibach HI. The vulvar epithelium differs from the skin: Implications for cutaneous testing to address topical vulvar exposures. Contact Dermatitis 2004;51:201-209.

48. Tourgeman DE, Gentzchein E, Stanczyk FZ, Paulson RJ. Serum and tissue hormone levels of vaginally and orally administered estradiol. Am J Obstet Gynecol 1999;180: 1480-1483.

49. Center for Devices and Radiological Health. Guidance for industry and FDA staff menstrual tampons and pads: Information for premarket notification submissions $(510(\mathrm{k}) \mathrm{s})$. 2005:510. Available at: www.fda.gov/medicaldevices/device regulationandguidance/guidancedocuments/uc m071781.htm Accessed May 8, 2018.

50. Kohen J. The history of the regulation of menstrual tampons. LEDA at Harvard Law School 2001.

51. McConnell J. Preventing urinary tract infections. Geriatr Nurs 1984;5:361-362.

52. BAHP: WVE report unsubstantiated, based on misinformation. Published 2018. Available at: https://www.prnewswire .com/news-releases/bahp-wve-report-unsubstantiated-basedon- misinformation-300661266.html Accessed June 17, 2018.

53. Atsdr. Toxicological profile for ethylbenzene. Available at: https://www.atsdr.cdc.gov/toxprofiles/tp110-c6.pdf Accessed February 22, 2019.

54. Paradichlorobenzene technical fact sheet. Available at: http://npic.orst.edu/factsheets/archive/PDBtech.html Accessed February 22, 2019.

55. D’Souza JC, Jia C, Mukherjee B, Batterman S. Ethnicity, housing and personal factors as determinants of VOC exposures. Atmos Environ 2009;43:2884-2892.

56. Sexton K, Mongin SJ, Adgate JL, et al. Estimating volatile organic compound concentrations in selected microenvi- ronments using time-activity and personal exposure data. J Toxicol Environ Heal Part A 2007;70:465-476.

57. Wallace LA, Pellizzari ED, Hartwell TD, Davis V, Michael LC, Whitmore RW. The influence of personal activities on exposure to volatile organic compounds. Environ Res 1989; $50: 37-55$.

58. Wallace LA. Human exposure to volatile organic pollutants: Implications for indoor air studies. Annu Rev Energy Environ 2002;26:269-301.

59. Chambers DM, Ocariz JM, McGuirk MF, Blount BC. Impact of cigarette smoking on volatile organic compound (VOC) blood levels in the U.S. population: NHANES 2003-2004. Environ Int 2011;37:1321-1328.

60. Wang X, Mukherjee B, Park SK. Associations of cumulative exposure to heavy metal mixtures with obesity and its comorbidities among U.S. adults in NHANES 2003-2014. Environ Int 2018;121:683-694.

61. Feminine Hygiene-United States $\mid$ Statista Market Forecast. Available at: https://www.statista.com/outlook/80040000/ 109/feminine-hygiene/united-states\#market- global Accessed February 21, 2018.
Address correspondence to: Sung Kyun Park, ScD Department of Epidemiology University of Michigan M5541 SPH II 1415 Washington Heights Ann Arbor, MI 48109-2029

E-mail: sungkyun@umich.edu 